\title{
As Transformações Geométricas no Currículo Prescrito de Matemática de Portugal
}

\section{The Geometric Transformations in the Mathematics Prescribed Curriculum in Portugal}

\author{
Júlio César Deckert da Silva*a; Ruy Cesar Pietropaolo ${ }^{a}$
}

\begin{abstract}
${ }^{a}$ Universidade Anhanguera de São Paulo, Programa de Pós-Graduação Stricto Sensu em Educação Matemática. SP, Brasil. *E-mail: deckertunibananhanguera@gmail.com
\end{abstract}

\begin{abstract}
Resumo
Em tempos atuais os currículos escolares têm sido objeto de discussão de muitos educadores, tanto no que se refere às finalidades de ensino dos conteúdos disciplinares como à utilização de métodos e procedimentos didáticos para o desenvolvimento desses conteúdos no contexto escolar. Além disso, o estudo das transformações geométricas tem sido enfatizado pelos educadores matemáticos como um recurso indispensável ao desenvolvimento do ensino da Geometria, viabilizando a construção de conceitos geométricos pelos alunos relacionados à congruência e à semelhança de figuras. As pesquisas referentes ao ensino de um determinado conteúdo escolar nos currículos prescritos conduzem grande parte dos pesquisadores a realizar investigações no campo dos estudos curriculares e da cultura escolar. No entanto, os estudos bibliográficos que se inserem nesses campos de pesquisa não podem indicar para os pesquisadores se as orientações dos currículos foram seguidas na prática durante o trabalho docente. Por meio desse estudo fazemos uma descrição das principais indicações do currículo prescrito de Portugal para o ensino das transformações geométricas no Ensino Fundamental II. As orientações didáticas da reforma curricular de Portugal para o ensino das transformações indicam que o estudo das isometrias deve ser priorizado pelos docentes do Ensino Fundamental II, com o intuito de fazer com que os alunos estabeleçam conexões entre a Geometria e a Álgebra. Acreditamos que nosso trabalho pode motivar reflexões dos educadores relacionadas à necessidade de renovação do ensino da Geometria através das transformações.
\end{abstract}

Palavras-chave: Transformações Geométricas. Currículo Prescrito. Reforma Curricular. Ensino Fundamental. Geometria.

\begin{abstract}
At the present school curriculum has been the subject of discussion for many educators, as regards both its teaching purposes of school contents and the utilization of didactic methods and procedures for the development of these contents in the educational context. Additionally, the study of geometric transformations has been emphasized by mathematics educators as an indispensable resource for the development of Geometry teaching, enabling the construction of geometric concepts by learners related to congruence and similarity of plane figures. Researches concerning by teaching of certain school content in the prescribed curriculum lead many researchers to carry on research in the field of curriculum studies and of school culture. However, these bibliographic studies that follow these research fields cannot indicate to researchers if curriculum guidelines were followed in practice during teachers' work. Through this study we make a description of the main indications of the prescribed curriculum in Portugal for teaching of geometric transformations in Elementary Teaching. Our methodological procedures consist of inquiry of the most recent mathematics curricular reform in Portugal on Elementary Education and on the analysis of the indications of this document for the teaching of geometric transformations. The didactic guidelines of the curricular reform in Portugal for the teaching of transformations indicate that the study of isometries must be prioritized by elementary school teacher, with the intention of making students establish connections between Geometry and Algebra. We believe that our paper can be motivate reflections on the part of educators raised by the need for renewal of Geometry teaching by transformations.
\end{abstract}

Keywords: Geometric Transformations. Prescribed Curriculum. Curricular Reform. Elementary Teaching. Geometry.

\section{Introdução}

Nosso trabalho foi concebido a partir de nossa tese de doutorado em desenvolvimento, a qual se concentra na linha de Estudos relacionada à Formação Docente, campo em que realizamos uma pesquisa bibliográfica documental inspirada nas teorias dos Estudos Curriculares, as quais têm sido enfatizadas nas pesquisas mais recentes de estudiosos do campo educacional, tal como podemos observar no artigo intitulado "O currículo como narrativa inclusiva na perspectiva de Ivor Goodson", publicado na revista eletrônica Brazilian Journal of Development (Beche, Ripa e Ventura (2020).
Nesse trabalho os autores utilizam as convicções do teórico britânico Ivor Goodson (2005) para analisar as orientações didáticas do programa curricular do Centro de Educação a Distância da UDESC referentes aos processos de inclusão de alunos especiais, procurando identificar aspectos intrínsecos à sociologia do currículo escolar e às práticas curriculares que contemplam o trabalho docente. Por meio de nosso estudo objetivamos analisar o desenvolvimento do conteúdo transformações geométricas na recente reforma curricular de Portugal para o Ensino Fundamental II. Optamos por analisar o currículo de Portugal devido aos progressos obtidos pelo 
país nas avaliações do PISA nos últimos anos. Dessa maneira, com o objetivo de melhor direcionarmos nossas investigações foi consultado o programa curricular intitulado Aprendizagens Essenciais: articulação com o perfil dos alunos para o Ensino Fundamental (Portugal, 2018).

Assim, procuramos embasar nossas concepções nas teorias de Julia (2001) a respeito da cultura escolar e nos princípios de Viñao (2007) e de Sacristán (2013) para discutir os principais aspectos das reformas educacionais. Esperamos que esse estudo possa contribuir para as reflexões dos educadores sobre os diferentes caminhos a serem seguidos no ensino da Geometria, bem como na adoção de novos métodos didáticos no ensino dos conteúdos matemáticos.

\section{Fundamentação Teórica}

A cultura que historicamente emergiu do contexto escolar e que, dentre outras finalidades, contempla as práticas educativas associadas aos processos de ensino e de aprendizagem, tem sido atualmente investigada por estudiosos que intentam compreender o desenvolvimento do campo educacional. Hoje, a cultura escolar se constitui como um campo de pesquisa importante por possibilitar aos pesquisadores estudar o contexto escolar e suas finalidades educacionais. (Julia, 2001)

Em sua pesquisa, Julia (2001) salienta que essa cultura é constituída pelas relações que são determinadas entre um conjunto de regulamentos pelos quais os conhecimentos pertinentes ao ensino escolar são definidos, bem como as atividades escolares referentes ao desenvolvimento desses conhecimentos e por um conjunto no qual estão imersas as práticas pedagógicas que refinam esses conhecimentos, adaptando-os ao ensino e agregando as atividades escolares ao campo educacional.

[...] Para ser breve, poder-se-ia descrever a cultura como um conjunto de normas que definem conhecimentos a ensinar e condutas a inculcar, e um conjunto de práticas que permitem a transmissão desses conhecimentos e a incorporação desses comportamentos [...] (Julia, 2001, p.10).

Julia (2001) enfatiza que as instituições de ensino, para serem compreendidas pelos pesquisadores, devem ser analisadas por meio de sua funcionalidade interna, e não pelos processos externos à sua dinâmica funcional. Dessa maneira, os documentos normatizadores do contexto escolar, os quais determinam as suas finalidades educativas, são fontes de estudo importantes para consultas.

As disciplinas representam construções específicas das instituições de ensino que possibilitam aos pesquisadores estudar os pressupostos dos sistemas educacionais.

A análise precedente remete-nos a um estudo daquilo que hoje se chama disciplinas escolares: estas não são nem uma vulgarização nem uma adaptação das ciências de referência, mas um produto específico da escola, que põe em evidência o caráter eminentemente criativo do sistema escolar [...] (Julia, 2001, p. 33).

A cultura escolar contempla as funções educativas das instituições de ensino, as quais interagem significativamente na reestruturação do seu trabalho. Nos currículos essa cultura está presente. Portanto, as modificações curriculares pelas quais são reformuladas as disciplinas constituem-se, dentre outros fatores intrínsecos ao campo educacional, por meio de novos pressupostos culturais do ensino escolar. Essas disciplinas explicitam em seu desenvolvimento os fundamentos que alicerçam essa cultura, os quais predominam nas práticas escolares e nos processos de ensino (Julia, 2001).

Em nossa pesquisa investigamos as finalidades pelas quais o ensino das Transformações Geométricas foi prescrito no currículo português de Matemática do Ensino Fundamental II, a fim de motivar reflexões dos educadores acerca da elaboração de novas reformas curriculares. Dessa forma, procuramos fundamentar nossas discussões no campo dos estudos curriculares, um campo de pesquisa que têm possibilitado aos pesquisadores compreender o funcionamento do contexto escolar, bem como os princípios estruturantes dos processos de ensino.

Embora o campo dos estudos curriculares como área de pesquisa não intencione especificamente solucionar as problemáticas do campo educacional, seus estudos propiciam aos pesquisadores análises mais consistentes dessas problemáticas.

Independentemente da época em que é instituído, o currículo contempla os preceitos modernos do campo educacional, adequando o trabalho desse campo ao contexto social no qual é concebido. Os programas curriculares são implementados mediante princípios sociopolíticos distintos, os quais determinam as funções do campo disciplinar. Esses programas motivam questionamentos nos pesquisadores referentes às finalidades do contexto escolar no ensino dos conteúdos.

Os currículos constituem fontes de estudos imprescindíveis às pesquisas referentes ao campo educacional. A análise dessas fontes possibilita aos pesquisadores compreenderem a construção dos processos organizativos que norteiam as atividades do campo educacional, bem como o desenvolvimento do ensino das disciplinas. As disciplinas escolares constituem outra maneira de investigar os pressupostos dos currículos que contemplam os sistemas educacionais.

Para Sacristán (2013), os currículos possuem dupla finalidade no contexto escolar, sendo sistematizadores e também unificadores dos processos de ensino e de aprendizagem. Os currículos determinam novas funções educativas para as disciplinas escolares. Logo, esses documentos representam recursos que, dentre outras funções, promovem externamente o controle do contexto escolar, no qual se produz cultura, orientando efetivamente o seu funcionamento e o seu ensino. É pelos currículos que se podem planejar as atividades do campo disciplinar e determinar padrões adequados para o desenvolvimento dos processos de ensino.

Seja por bem ou por mal, o fato é que o ensino, a aprendizagem e seus respectivos agentes e destinatários - os 
professores e alunos - tornaram-se mais orientados por um controle externo, uma vez que este determinou a organização da totalidade do ensino por meio do estabelecimento de uma ordem sequenciada. Um dos efeitos desse regramento foi o reforço da distinção entre as disciplinas e a determinação concreta dos conteúdos que os professores deveriam cobrir, bem como o refinamento dos métodos de ensino. Dessa maneira, o conceito de currículo delimitou as unidades ordenadas de conteúdos e períodos que têm um começo e um fim, com um desenvolvimento entre esses limites, impondo uma norma para a escolarização. Não é permitido fazer qualquer coisa, fazer de uma maneira qualquer ou fazê-la de modo variável (Sacristán, 2013, p.18).

Os conteúdos escolares representam componentes culturais que possibilitam a construção dos conhecimentos do contexto escolar. No campo cultural há significados distintos para os elementos estruturantes do ensino. É por meio da interatividade desses elementos que se concebe, no contexto escolar, o conhecimento. Os currículos não são documentos que determinam as realidades escolares, mas são imprescindíveis ao campo educacional por possibilitarem nesse campo a inserção de aspectos culturais na construção do ensino e em seu desenvolvimento (Sacristán, 2013).

Embora o campo pedagógico, em suas finalidades, não se limite apenas a viabilizar o ensino dos conteúdos escolares, são esses conteúdos que permitem a aplicação dos pressupostos dos currículos nas instituições de ensino. Com isso, o contexto escolar se desenvolve por meio das reformulações didáticas desses conteúdos.

Segundo Sacristán (2013), os pressupostos dos currículos são ineficazes para aprimorar o trabalho do contexto escolar se os educadores são inaptos para promover as capacidades que os estudantes necessitam para desenvolver de maneira coesa suas aprendizagens. Mesmo que as orientações dos currículos proponham aos professores novos procedimentos e métodos didáticos para o ensino dos conteúdos, a ausência de estratégias eficazes para o desenvolvimento desses conteúdos acarreta falhas nos processos de ensino (Sacristán, 2013).

Para esse pesquisador, as distintas concepções dos estudiosos referentes às finalidades dos currículos nos sistemas educacionais estabeleceram outras funções para o trabalho pedagógico no ensino das disciplinas, tal como a criação de competências associadas aos processos de aprendizagem.

Em níveis educacionais precedentes ao universitário, essas competências são recursos sistematizadores e também controladores dos preceitos curriculares relacionados ao ensino dos conteúdos, planejando-os e organizando-os em uma configuração distinta das fragmentações disciplinares habitualmente explicitadas pelas listas de conteúdos, as quais são extensas e inaplicáveis ao ensino, para que os professores possam promover de maneira consistente as aprendizagens do público estudantil.

Nos níveis não universitários, as competências estão sendo utilizadas como um procedimento para regular e controlar os objetivos e conteúdos mínimos do currículo exigido de todos, como uma guia para ordená-los a partir de uma lógica distinta à dos agrupamentos das matérias, disciplinas ou áreas tradicionais, assim como para orientar as atividades de ensinar-aprender. A regulação se realiza por meio das prescrições escritas correspondentes impostas a todo o sistema e aos fabricantes dos textos escolares [...] (Sacristán, 2013, p.278).

Em sua pesquisa Viñao (2007) enfatiza que os sistemas educacionais se desenvolvem por meio de uma interação entre as diferentes culturas escolares e os programas curriculares a qual define como "gramática escolar". Através dessa interação as escolas passam a seguir um direcionamento no qual definem, em conjunto com docentes e legisladores suas finalidades educacionais. Dessa maneira os sistemas educacionais, ao sofrerem modificações, alteram o funcionamento de todas as escolas que vinculam.

Essas modificações podem permanecer vigentes durante muitos anos quando são provenientes do campo sócioeducativo ou podem ser instauradas parcialmente nas escolas por uma necessidade de reorganização curricular. Embora tenham procedências distintas, essas mudanças se desenvolvem no contexto escolar de maneira integrada e ambas devem ser analisadas pelos pesquisadores que estudam as relações entre os pressupostos das reformas curriculares e sua relação com a cultura escolar.

Os currículos prescritos, desde a sua elaboração seguem uma cultura distinta daquela que provém das práticas escolares. Trata-se da cultura das autoridades reformadoras que visam estruturar esses documentos mediante aos seus interesses administrativos, procurando reorganizar as diversas atividades escolares de maneira conservadora, sistemática e até mesmo burocrática, por meio da qual os aspectos formais das reformas e os objetivos dos reformadores são muito enfatizados.

Para Viñao (2007) as macroreformas, ao serem implantadas promovem alterações na cultura das escolas. Os professores, por não conhecerem a cultura reformadora não conseguem compreender as prescrições curriculares e integrálas ao seu trabalho. Assim as reformas sofrem problemas para serem aplicadas, são muitas vezes ignoradas pelos docentes que, por sua inaptidão cultural, optam por seguir aleatoriamente pressupostos burocráticos e diante desses fatos essas macroreformas se deparam com o insucesso.

As macroreformas estruturais e curriculares elaboradas desde a consolidação dos campos político e administrativo modificam, pois, a cultura das instituições escolares. Em plena supremacia, no geral elas se opõem por sua característica e natureza omnicompreensiva - esta última, assim como, de modo particular, a cultura acadêmica docente, todo o conjunto de crenças, mentalidades, práticas de interação e de trabalho adquiridas no decurso do tempo, enraizadas e transmitidas, mas não imutáveis, que passam de uma geração para outra, contra as ações dos professores diante de suas tarefas cotidianas, em suas aulas ou fora delas no modo de conceber e aplicar no seu trabalho as prescrições e orientações administrativas. É daí que surgem os atrasos na aplicação das reformas, a desvalorização dos seus objetivos iniciais, sua substituição por procedimentos formais burocráticos e por último o evidente fracasso de todas elas. (Viñao, 2007, p. 11, tradução do autor). 
Durante o seu trabalho, os docentes sofrem muitas pressões para cumprir as determinações estabelecidas por autoridades internas ou externas ao contexto escolar. Em consequência dessas pressões e da falta de conhecimento de políticas educacionais os professores, em muitos casos, alegam não dispor de um período de tempo adequado para analisar ou seguir todas as recomendações dos programas curriculares.

\subsection{O Sistema de Ensino de Portugal}

O sistema educacional português está organizado em ciclos sequenciais. Inicia-se com a Pré-escola, com um ciclo dos 3 aos 6 anos de idade. Depois dessa etapa inicia-se o Ensino Básico (que equivale ao Ensino Fundamental), o qual se divide em três ciclos.

- $1^{\circ}$ ciclo com duração de 4 anos (dos 6 aos 10 anos de idade):

- $2^{\circ}$ ciclo com duração de 2 anos (dos 10 aos 12 anos de idade):

- $\quad 3^{\circ}$ ciclo com 3 anos de duração (dos 12 aos 15 anos de idade)

O $1^{\mathrm{o}}$ ciclo compreende do primeiro ao quarto ano de escolaridade. $\mathrm{O} 2^{\circ}$ ciclo compreende do quinto ao sexto ano. $\mathrm{E}$ o $3^{\circ}$ ciclo compreende do sétimo ao nono ano de escolaridade.

Após a conclusão do Ensino Básico, os alunos ingressam no Ensino Secundário (que é equivalente ao Ensino Médio). Esse nível de ensino constitui um ciclo com duração de três anos, dos 15 aos 18 anos de idade. O Secundário possui sete cursos distintos. Esses cursos são os seguintes: cursos profissionais, cursos científico-humanísticos, cursos artísticos especializados, cursos com planos de ensino próprios (cursos científico-tecnológicos), cursos de ensino e formação, cursos de aprendizagem e também Ensino Secundário na condição de ensino recorrente.

\section{O Currículo Prescrito de Portugal e o Ensino das Transformações Geométricas}

\subsection{O programa curricular do Ensino Básico}

A reforma curricular do Ensino Básico, denominada "Aprendizagens Essenciais", foi implantada no ano de 2018, pelo primeiro ministro Augusto Ernesto Santos Silva. Instituída pelo Decreto $n^{\circ}$ 55/2018 de 6 de Julho, essa reforma apresenta os objetivos a serem atingidos nos processos de ensino e de aprendizagem de matemática para os alunos dos três ciclos que estruturam o Ensino Básico.

As indicações do documento explicitam para os educadores que os processos de ensino e de aprendizagem de matemática têm como foco a compreensão dos conceitos matemáticos pelos estudantes. Dessa maneira, objetiva-se desenvolver as capacidades dos estudantes para utilizar os conhecimentos matemáticos em contextos diversificados, fazendo com que a matemática possa contribuir para a formação dos alunos, não somente no contexto escolar, mas também em toda a sua trajetória no âmbito pessoal, social e profissional.

Finalidades do ensino da Matemática
Respeitando os princípios de equidade e qualidade, o ensino da Matemática, ao nível da escolaridade básica, deve visar aprendizagens matemáticas relevantes e sustentáveis para todos os alunos. Neste sentido, privilegia-se uma aprendizagem da Matemática com compreensão, bem como o desenvolvimento da capacidade de os alunos em utilizála em contextos matemáticos e não matemáticos ao longo da escolaridade, e nos diversos domínios disciplinares, por forma a contribuir não só para a sua autorrealização enquanto estudantes, como também na sua vida futura pessoal, profissional e social. (Portugal, 2018, p. 2).

No Ensino Básico, noções e conceitos matemáticos devem ser compreendidos pelo aluno para viabilizar o seu desenvolvimento pessoal e lhe proporcionar a aquisição de elementos necessários para as aprendizagens de conteúdos disciplinares diversificados, isto é, o conhecimento matemático adquirido pelo aluno do Ensino Básico deve contribuir para o desenvolvimento de suas capacidades de aprendizagem durante toda a sua formação acadêmica, em qualquer área de conhecimento que o aluno escolha estudar, bem como em todas as atividades profissionais de sua preferência e nas etapas de sua formação como cidadão.

Na escolaridade básica, o ensino da Matemática deve, pois, proporcionar uma formação na disciplina centrada na aprendizagem que contribua para o desenvolvimento pessoal do aluno e lhe propicie a apropriação de instrumentos conceptuais e técnicos necessários na aprendizagem de outras disciplinas ao longo do seu percurso académico, qualquer que seja a área de prosseguimento de estudos escolhida. Deve contribuir igualmente para a atividade profissional por que venha a optar e para o exercício de uma cidadania crítica e participação na sociedade, com sentido de autonomia e colaboração, liberdade e responsabilidade. (Portugal, 2018, p.2).

Nesse nível procura-se desenvolver também uma formação em matemática, através da qual os estudantes tenham apreciação pelas aprendizagens dos conteúdos matemáticos, reconhecendo a importância da matemática não somente como uma disciplina escolar, mas como uma ciência que possui valores culturais e sociais que são fundamentais no desenvolvimento de diversos campos científicos, de tecnologias e em outras áreas do conhecimento.

No $2^{\circ}$ ciclo o estudo das transformações geométricas é enfatizado pelo currículo no bloco geometria e medida. Além do estudo das propriedades das figuras planas e dos sólidos tridimensionais e também dos cálculos de perímetros, de áreas e de volumes, o estudo das transformações de figuras no plano é prescrito pelo currículo. As orientações didáticas do documento sugerem para o professor explorar com os alunos o estudo da rotação e da reflexão como isometrias.

\section{Geometria e Medida}

Os alunos prossigam no desenvolvimento da capacidade de visualização e na compreensão de propriedades de figuras geométricas, alargando-se o estudo de sólidos geométricos e de figuras planas e o estudo das grandezas geométricas e das isometrias do plano. Neste ciclo, o perímetro é trabalhado com outras figuras geométricas, como o círculo e polígonos irregulares, e é introduzido o estudo das fórmulas para o cálculo de áreas e volumes - do triângulo e do círculo, e dos prismas retos e do cilindro, respectivamente. Nas isometrias 
dá-se especial atenção à reflexão e à rotação. (PortugaL, 2018, p. 49-50)

No $5^{\circ}$ ano do $2^{\circ}$ ciclo o estudo das figuras geométricas é prescrito pelo currículo com a finalidade de fazer com que os alunos construam figuras com régua e compasso. Os estudantes devem utilizar os conhecimentos adquiridos em anos do $1^{\circ}$ ciclo para construir as figuras, como no caso da construção dos triângulos, na qual as noções e os conceitos de segmentos e de ângulos são muito importantes.

Para $06^{\circ}$ ano as orientações didáticas do currículo sugerem para o professor desenvolver o estudo das isometrias propondo para os alunos que construam e identifiquem reflexões e rotações de figuras representadas no plano. Além disso, os estudantes devem identificar e analisar as simetrias rotacionais e de reflexão das figuras geométricas em diferentes contextos, tanto na matemática como na natureza, nas artes, no cotidiano, entre outros.

Identificar e construir o transformado de uma dada figura através de isometrias (reflexão axial e rotação) e reconhecer simetrias de rotação e de reflexão em figuras, em contextos matemáticos e não matemáticos, prevendo e descrevendo os resultados obtidos. (Portugal, 2018, p.63).

As indicações do documento explicitam para o professor que o estudo das transformações pode ser desenvolvido utilizando-se diferentes recursos didáticos para motivar as aprendizagens dos estudantes em diversas situações que favoreçam a construção de noções e conceitos geométricos.

Nesse ano de escolaridade o estudo das transformações geométricas tem como finalidade fazer com que os alunos realizem reflexões e rotações de figuras no plano de maneira algébrica, modificando as coordenadas dos vértices das figuras e explorando as propriedades geométricas das figuras obtidas por transformação. Também objetiva-se ampliar os conhecimentos dos alunos referentes às aplicações das simetrias de figuras geométricas em diferentes contextos de aprendizagem para facilitar a sua compreensão acerca da importância da utilização dessas transformações na prática.

No $3^{\circ}$ ciclo do Ensino Básico o ensino da Geometria é prescrito com ênfase no estudo das transformações geométricas. No bloco Geometria e Medida aprofundase o estudo das propriedades geométricas das figuras, das grandezas e também das transformações com o objetivo de fazer com que os estudantes compreendam propriedades e conceitos geométricos relacionados ao estudo da congruência e da semelhança de figuras e desenvolvam capacidades relacionadas à visualização.

Geometria e Medida

Os alunos prossigam no desenvolvimento da capacidade de visualização e na compreensão de propriedades de figuras geométricas, alargando-se o estudo de sólidos geométricos e de figuras planas e das grandezas geométricas, bem como das transformações geométricas. (Portugal, 2018, p. 67)

Para o $7^{\circ}$ ano as indicações do currículo sugerem para o professor explorar com os alunos as propriedades geométricas dos polígonos para que possam classificar essas figuras por meio de suas propriedades.

No $8^{\circ}$ ano as orientações didáticas do currículo sugerem para o professor propor para os alunos que identifiquem e representem as isometrias, inclusive as translações de figuras geométricas no plano utilizando noções de vetores e também por meio de composições de duas ou mais transformações. Para construir as figuras geométricas através de transformações os estudantes podem utilizar todos os tipos de materiais, inclusive softwares matemáticos, com a finalidade de habilitar os alunos a aplicarem as transformações geométricas em diversos contextos para que possam compreender as relações entre as propriedades das figuras.

Reconhecer e representar isometrias, incluindo a translação associada a um vetor, e composições simples destas transformações, usando material e instrumentos apropriados, incluindo os de tecnologia digital, e utilizá-las em contextos matemáticos e não matemáticos, prevendo e descrevendo os resultados obtidos. (Portugal, 2018, p.72).

Para o $9^{\circ}$ ano as indicações do currículo sugerem para o professor desenvolver o estudo das transformações por meio de construções geométricas. Os alunos devem construir e identificar os seguintes lugares geométricos: circunferências, círculos, bissetrizes e mediatrizes. Objetiva-se capacitar os estudantes a utilizar essas construções na resolução de problemas de geometria. Durante a realização das atividades de construção de lugares geométricos os alunos podem utilizar diversos materiais de manipulação, tais como malhas geométricas, softwares matemáticos e também calculadoras.

As construções geométricas de mediatrizes e de bissetrizes são importantes para a compreensão dos alunos referente aos conceitos de congruência, pois as atividades de construção podem ser exploradas pelos estudantes para que possam identificar e analisar a invariância geométrica obtida através de simetrias. Os alunos podem observar a equidistância dos pontos das figuras, bem como a preservação das medidas e dos ângulos das figuras em relação ao eixo de simetria.

\section{Considerações Finais}

Por meio da análise das prescrições do programa curricular português do Ensino Fundamental, observamos que o ensino das transformações geométricas tem como finalidade viabilizar aos alunos o desenvolvimento de noções e conceitos geométricos através da identificação, da caracterização, da visualização e da compreensão da invariância geométrica das figuras obtidas por transformações.

Além disso, o estudo das transformações, em especial o estudo das isometrias, está integrado ao ensino de Geometria com o objetivo de auxiliar os estudantes a ampliarem os seus conhecimentos no estudo da congruência e da semelhança de figuras geométricas. Dessa maneira, podemos notar que o currículo prescrito de Portugal, tal como enfatizado por Sacristán (2013), exerce dupla finalidade no contexto escolar, promovendo a sistematização e a unificação dos processos de ensino e de aprendizagem de Geometria. 
No entanto, as divergências existentes entre a cultura reformadora e a cultura dos docentes, tal como explicitado por Viñao (2007) pode fazer com que o ensino das transformações geométricas não seja desenvolvido de forma adequada nas escolas, devido ao desconhecimento que muitos docentes do Ensino Fundamental demonstram em relação a esse conteúdo.

\section{Referências}

Beche, R. C. E., Ripa, R. \& Ventura, L. (2020). O currículo como narrativa inclusiva de Ivor Goodson. Brazilian Journal of Development, 6(5).
Goodson, I. F. (2005). Currículo: teoria e história. Petrópolis: Vozes.

Julia, D. (2001). A cultura escolar como objeto histórico. História da Educação, Campinas/SP, 1, 10-47.

Portugal. (2018). Ministério da Educação. Aprendizagens essenciais: Articulação com o perfil dos alunos. Lisboa, pp. 2-116.

Sacristán, J. G. (2013). Saberes e incertezas sobre o currículo. Porto Alegre: Penso.

Viñao, (2007). A. Culturas escolares y reformas (sobre la natureza histórica de los sistemas e instituciones educativas). Historia de la educación, Múrcia, 9(13), 1-25. 